\title{
MANAJEMEN INFORMASI PENGELOLAAN SURAT MASUK DAN KELUAR PADA SD NEGERI GENURIT KRAMATWATU SERANG
}

\author{
Ahmad Sofan Ansor ${ }^{1}$, Mona Setia Ningrum ${ }^{2}$ \\ ${ }^{1,2}$ Politeknik PGRI Banten \\ email: sofanansor65@gmail.com \\ email:monasetianingrum@gmail.com
}

\begin{abstract}
Information management of incoming and outgoing mail at SDN GenuritSerang still uses manual notes. The process of managing incoming and outgoing mail information is made by a computer program application to find out quickly and accurately the information data received by the school. The purpose of the communication technology adaptation program is to support the teaching and learning process. Improving the quality of school management through the school information management system. Learned the obstacles in managing incoming and outgoing mail manually and replacing it with a Microsoft Office computer data information system. Making the application program through three stages, namely the analysis stage, the design stage and the implementation stage. This school incoming and outgoing mail information system can help make work easier, speed up data searching and can reduce human errors.
\end{abstract}

Keywords: information management, incoming and outgoing letters, SDN Genurit, microsoft office

\section{ABSTRAK}

Manajemen informasi pengelolaan surat masuk dan keluar di SDN Negeri Genurit Serang masih menggunakan catatan secara manual. Proses pengelolaan informasi surat masuk dan keluar dibuat aplikasi program komputer untuk mengetahui dengan cepat dan akurat data informasi yang diterima sekolah. Tujuan program adaptasi teknologi komunikasi untuk menunjang proses belajar mengajar. Peningkatan kualitas manajemen sekolah melalui sistem manajemen informasi sekolah. Dipelajari hambatan-hambatan dalam pengelolaan surat masuk dan keluar secara manual dan mengganti dengan sistem informasi data komputer Microsoft Office. Pembuatan program aplikasi melalui tiga tahapan yaitu tahapan alisis, tahap desain dan tahap implementasi. Sistem informasi surat masuk dan keluar sekolah ini dapat membantu memudahkan pekerjaan, mempercepat pencarian data dan dapat mengurangi kesalahan manusia.

Kata kunci: manajemen informasi, surat keluar masuk, SDN Genurit, microsoft office.

\section{PENDAHULU}

Perkembangan Ilmu pengetahuan dan teknologi computer setiaptahunnya selalu berkembang dengan pesat sehingga menyebabkan masyarakat sangat terbantu oleh informasi yang cepat dan akurat. Kemajuan teknologi informasi di bidang komputer dapat memecahkan masalah-masalah yang sering dialami dalam kehidupan sehari-hari seperti pengelolaan surat keluar masuk selama ini menggunakan sistem catatan manual sehingga ketika dibutuhkan untuk mencari data surat masuk cukup lama untuk diketahui. Oleh karena 
itu, keberadaan computer sangatlah membantu karena program komputer mampu melakukan pengolahan dan penyimpanan data dalam skala yang cukup besar dengan cepat dan akurat.

Manajemen sekolah adalah pengelolaan pendidikan meliputi kegiatan perencanaan, pengorganisasian, pelaksanaan dan evaluasi hasil pendidikan. Informasi Pendidikan dirancang sesuai dengan standar dengan jejaring pendidikan nasional dimana program pengembangan infrastruktur jaringan akan terhubung secara nasional. Segala kebutuhan pelaporan dari sekolah ke Dinas Pendikan Daerah maupun untuk kebutuhan Kementerian Pendidikan dan Kebudayaan (Kemendikbud) dapat dilakukan dengan mudah. Dengan adanya sistem informasi pendidikan ini manajemen pendidikan sekolah menjadi lebih mudah dan terkontrol.

Kebutuhan mendata untuk surat masuk dan keluar dengan metode komputerisasi tentu akan sangat membantu kegiatan sekolah. Penyusunan pogram komputer dengan Microsof Access dilakukan dengan tiga tahapan. Metode yang digunakan dalam pembuatan program sistem informasi surat masuk dan keluar sekolah menggunakan metode deskriptif dan penggunaan perancangan sistem digunakan adalah waterfall, dalam software lifecycle (Waterfall Model). Model ini memisahkan dan membedakan tahapan-tahapan spesifikasi dan pengembangan, dengan menggunakan tiga langkah yaitu analisis, desain dan implementasi.

SD Negeri Genurit adalah sekolah yang terletak di jalan Banten lama Desa Terate Kecamatan Kramatwatu didirikan pada tahun 1969. Dalam pengelolaan surat masuk dan surat keluar di bagian Tata usaha masih menggunakan cara manual menggunakan buku besar, sehingga bisa menyebabkan beberapa masalah, diantaranya; pada saat pencarian data akan membutuhkan waktu yang sangat lama, semakin banyak surat masuk dan surat keluar maka akan mengakibatkan terjadinya penumpukan catatan dan penumpukan arsip, pencatatan dengan buku menimbulkan biaya yang besar, selain itu pencatatan pada buku bisa menimbulkan data robek, hilang, terkena tumpahan minuman dan karena binatang perusak kertas.

Berdasarkan gambaran pengelolaan data surat masuk dan keluar dapat disimpulkan bahwa perlu adanya teknologi informasi untuk meningkatkan kinerja guru atau tenaga kependidikan menjadi lebih efektif dan efisien. Dengan adanya sistem informasi ini, pengelolaan surat masuk dan surat keluar dalam pencarian data akan lebih mudah, menghemat penggunaan buku, waktu serta ruang dalam penyimpanan data. 


\section{TINJAUAN TEORITIS}

Manajemen sebagai suatu kemampuan atau keahlian yang menjadi cikal bakal manajemen suatu profesi. Manajemen suatu ilmu menenkankan perhatian pada keterampilan dan kemampuan manajerial yang diklasifikasikan menjadi keterampilan teknikal, manusiawi dan konseptual. Pendidikan merupakan proses timbal balik antara kepribadian individu dalam penyesuaian diri dalam lingkungan pendidikan. Manajemenpendidikanmerupakan proses pelaksanaan tugas dengan mendayagunakan segala sumberdaya secara efisien untuk mencapai tujuan secara efektif (Mulyati dan Komariah, Tim dosen UPI,2009). Menurut GR Terry difininsi manajemen adalah Planning, Organizing, Actuating, Controlling yang dikenal dengan POAC. (Ansor dan Mutahidah, 2016).

Informasi adalah satu atau lebih data yang telah dilakukan proses pengolahan menjadi bentuk yang berarti lebih dan berguna bagi penerimanya (Dasril Aldo, 2020). Informasi yang diterima memiliki makna yang lebih mudah dicerna dan dapat lebih dilakukan pengambilan kegiatan berikutnya. Sedang menurut Deni Darmawan (2012:5) menyatakan Informasi merupakan sesuatu yang lebih sementara (transitory) daripada pengetahuan. Sedang dalam buku Sistem Informasi Manajemen (2021:41) menyatakan bahwa sistem Informasi adalah suatu rangkaian yang komponen-komponennya saling berkaitan dalam mengumpulkan, memproses, menyimpan, dan mendistribusikan informasi untuk mendukung pengambilan keputusan dan mengendalikan perusahaan.

Sistem informasi manajemen merupakan sebuah sistem manusia/mesin yang terpadu untuk menyajikan informasi guna mendukung operasi, manajemen dan pengambilan keputusan dalam organisasi (Mirfani dan Suryadi Tim dosen UPI, 2009). Hal ini menunjukan peran penting yang saling berkaitan antara manusia dan mesin, dalam hal ini teknologi komputer. Program komputer akan menghasilkan data berupa informasi yang sangat berguna bagi pengambil keputusan/manajemen sekolah. Fungsi informasi disini memiliki peran dalam nilai efisiensi dan efektivitas.

Surat masuk adalah surat-surat yang diterima oleh suatu organisasi/ perusahaan yang berasal dari seseorang atau dari suatu organisasi (Ayu Dewi Lestari, 2014). Dalam hal ini surat yang masuk dan diterima sekolah. Sedang surat keluar adalah semua surat yang dibuat/dikeluarkan oleh suatu perusahaan atau organisasi untuk diberikan kepada pihak lain, baik kepada perorangan maupun perusahaan/organisasi (M.Prawiro, 2018). Dalam hal ini surat yang dikeluarkan dari sekolah. 
Menurut Madcoms dalam bukunya yang berjudul kupas tuntas Microsoft Access2016 menyatakan Microsoft access merupakan sistem manajemen data base yang sudah banyak digunakan dan merupakan bagian dari Microsoft office. Menurut Sarwandi (2017:1) dalam bukunya yang berjudul jago micsoft access 2016 menyatakan Microsoft office access atau yang lebih dikenal Microsoft access adalah sebuah program aplikasi basis data komputer relasional yang ditujukan untuk kalangan rumahan dan perusahaan kecil menengah. Aplikasi microsof office diatas digunakan untuk membuat program keluar masuk surat di SD Negeri Gerit tempat peneltian ini.

Entity Relationship diagram (ERD) merupakan teknik yang digunakan untuk memodelkan kebutuhan data dari suatu organisasi, biasanya oleh System Analys dalam tahapan analisis persyaratan proyek pengembangan sistem. ERD merupakan suatu model untuk menjelaskan hubungan antar data dalam basis data berdasarkan objek-objek dasar data yang mempunyai hubungan antar relasi. ERD untuk memodelkan struktur data dan hubungan antar data, untuk menggambarkannya digunakan beberapa notasi dan simbol.

Data Flow Diagram (DFD) merupakan suatu cara atau metode untuk membuat rancangan sebuah sistem yang mana berorientasi pada alur data yang bergerak pada sebuah sistem. Dalam pembuatan Sistem Informasi, DFD sering digunakan. DFD dibuat oleh para analis untuk membuat sebuah sistem yang baik. Dimana DFD ini nantinya diberikan kepada para programmer untuk melakukan proses coding data. Dimana para programmer melakukan sebuah coding sesuai dengan DFD yang dibuat oleh para analis sebelumnya. Flowchart atau bagan alir adalah bagan (Chart) yang menunjukkan alir (Flow) di dalam program atau prosedur sistem secara logika. Bagan alir (Flowchart) digunakan terutama untuk alat bantu komunikasi dan untuk dokumentasi. System flowchart dapat didefinisikan sebagai bagan yang menunjukan arus pekerjaan secara keseluruhan dari sistem.

Penerapan sistem informasi manajemen sekolah sangat penting dalam mendukung kegiatan pendataan sekolah seperti dapodik dan layanan informasi sekolah sehingga menunjang kegiatan belajar mengajar. Bagian tata usaha sangat penting untuk meninjang pengolahan data sekolah. Untuk diperlukan kemampuan mengolah data sekolah melalui layanan teknologi komputer (Musdalifah, 2016). Sistem pengolahan data sekolah yang lebih luas seperti satu kabupaten seperti data sekolah, data sarana prasarana tiap sekolah, data kependidikan, data peserta didik dibutuhkan pengolahan data dengan sistem yang 
lebih baik dan dengan impor data menggunakan program exel. (Pujianto dan Rasidi, 2015).

\section{METODE PENELITIAN}

Pendekatan pada penelitian ini dengan menggunakan pendekatan kualititatif dalam pengumpulan data dan penyusunan program Microsoft Office yang menggunakan tahapantahapan perencanaan (desain), metodologi, teknik, alat (tools) dan dokumentasi. Metodologi membimbing peneliti dari fase-fase dan sub fase memilih metode, teknik, prosedur apa yang tepat dan tools apa yang digunakan sehingga setiap tahapan penelitian dilakukan dengan tepat. (Zainal A Hasibuan, 2007). Penyususan proses penelitian dilakukan secara logis dengan penalaran yang deduktif yaitu proses berpikir yang berusaha menghubungkan dengan fakta-fakta yang diketahui menuju hasil kesimpulan. Hubungan satu data dengan data lain terhubung secara integrasi dalam suatu sistem.

Pengumpulan data penelitian mengenai surat masuk dan keluar SDN Genurit berdasar hasil wawancara dengan beberapa informan yairu guru-guru di sekolah dan temuan faktual lapangan di SDN Genurit Banten. Peenelitian dilakukan mulai minggu ke IV bulan Januari 2021 sampai pertengahan bulan Maret 2021. Hasil data kemudian dianalisis secara deskriptif untuk mendapatkan gambaran yang utuh mengenai objek yang menjadi bahan penelitian. Rumusan masalah merupakan suatu pertanyaan yang dicarikan jawaban melalui pengumpulan data. Dalam hal ini data surat masuk dan keluar SD Genurit dengan berbagai permasalahan yang ada. Penyusunan program komputer melalui Microsoff Access yang dapat memformulasikan dan menyajikan hasil data secara komprehensif. Dibutuhkan hardware dan software dalam menyusun program informasi surat masuk dan keluar serta perancangan desain program yang menghubungkan masing-masing tahapan oleh seorang programmer (brainware).

\section{HASIL DAN PEMBAHASAN}

\section{Objek Penelitian dan Permasalahannya}

SD Negeri Genurit merupakan sekolah negeri yang terletak di jalan Banten Lama Desa Terate Kecamatan Kramatwatu Kabupaten Serang Provinsi Banten. Sekolah ini didirikan pada tahun 1969. SD Negeri Genurit merupakan sekolah dasar negeri yang bertujuan untuk mendidik siswa/siswi atau peserta didik baru dengan motto "Cerdas dalam pemikiran, santun dalam bersikap" sejalan dengan tujuan sekolah yang melatih peserta didik agar 
memiliki keterampilan dan kecakapan dasar serta mampu menggali kompetensi dalam diri siswa atau siswinya (Observasi pada 27 Januari 2021).

Struktur organisasi sekolah terdiri dari Kepala Sekolah, Bendahara, Sekretaris (Tata Usaha) dan enam orang guru. Menempati lahan tanah seluas $3005 \mathrm{~m} 2$ dengan menempati gedung permanen sendiri. Ruang kelas ada 6 lokal, ada satu ruang Kepala Sekolah, ruang guru dan ruang perpustakaan. Semua tenaga pengajar guru berjumlah 9 (sembilan) orang sudah berkualifikasi sarjana S-1. PNS berjumlah 7 (tujuh) orang dan guru berstatus honorer 2 (dua) orang. (Luhis SPd, Kepsek Genurit, wawancara 27 Januari 2021).

Permasalahan yang menjadi pembahasan pada penelitian ini yaitu penyimpanan data surat masuk dan keluar dicatat secara manual dalam buku besar. Pencatatan melalui manual ini banyak kelemahan dan kendala seperti akses mendapatkan informasi sangat lambat. Buku dari kertas ini juga mudah hilang bagian tertentu, mudah kotor, robek, dan rusak dimakan usia. Untuk menyelesaikan permasalahan ini peneliti mencoba membuat program informasi berupa program kumputer yang mudah dibaca dan diakses.

\section{Desain tahapan penyusunan sistem informasi}

Setelah data surat masuk dan keluar dari sekolah didata, dipilah dan dianalisis kemudian diproses melalui sistem komputerisasi. Proses menggunakan hardware berupa laptop intel RAM 8 GB dan software dari Windows 10 dan Microsoft Office 13. Peneliti mengolah data bersama bantuan seorang programmer untuk menyusun program aplikasi surat keluar masuk sekolah. Tahap desain merupakan tahapan berupa penggambaran, perencanaan pembuatan dengan menyatukan beberapa elemen terpisah ke dalam suatu kesatuan yang utuh untuk memperjelas bentuk dari suatu sistem.

Uraian dari flow map sistem berjalan secara manual dicatat dalam buku besar adalah sebagai berikut:

1) Tata usaha menerima surat dari pengirim kemudian mencatat surat masuk kedalam buku agenda surat masuk.

2) Jika sudah dicatat selanjutnya Tata usaha memberikan surat masuk kepada kepala sekolah

3) Kepala Sekolah menanggapi surat masuk tersebut

4) Kepala sekolah meminta Tata Usaha untuk mengarsipkan surat masuk dan meminta untuk membalas surat masuk kepada pengirim.

5) Tata usaha membuat surat keluar lalu mencatatnya ke dalam buku agenda selanjutnya menyerahkan surat keluar kepada kepala sekolah 
6) Kepala sekolah menandatangani surat keluar lalu menyerahkan kepada tata usaha

7) Tata usaha mengarsipkan surat keluar dan memberikan laporan surat masuk dan surat keluar kepada kepala sekolah

8) Tata usaha mengirim surat keluar kepada pengirim selesai Kelemahan pengelolaan surat masuk dan surat keluar berjalan secara manual (Zaini Mubarok SPd, TU, wawancara 03 Februari 2021)

Kemudian dalam sistem yang diusulkan dengan menggunakan aplikasi pembukuan surat keluar masuk sekolah, terdapat beberapa kelebihan diantaranya untuk mempermudah tata usaha dalam melakukan penginputan data secara otomatis, keamanan data dapat terjaga sehingga terhindar dari berbagai kerusakan, selain itu pekerjaan tata usaha menjadi lebih mudah dan dapat diselesaikan dengan benar dan tepat waktu. Proses pengolahan data dapat dilihat dalam uraian diagram konteks. Uraian Diagram Konteks dengan susunan berikut:

1) Sistem menerima data pengirim dan data surat masuk dari pengirim

2) Sistem memproses data surat masuk

3) Sistem menerima data surat keluar dari Tata usaha

4) Sistem memproses data surat keluar

5) Sistem memberikan keterangan surat keluar kepada pengirim

6) Sistem memberikan laporan surat masuk dan surat keluar kepada kepala sekolah (Hasil analisis observasi, 03 Februari 2021)

Hubungan antar entitas yaitu hubungan antara sesuatu yang memiliki keberadaan yang unik dan berbeda yang menggambarkan model komunikasi dan pemrosesan internal untuk membedakan dokumen. Kemudian dibuat derajat dan kardinality ratio, dimana dibuat susunan basis data berdasarkan derajat relasi maksimum entitas dengan entitas pada himpunan data lain. Partisipan contrain menunjukan apakah keberadaan suatu entitas bergantung penuh atau tidak dengan entitas relasinya. Batasan (contrain) adalah jumlah minimum relasi dimana tiap entitas dapat ikut partisipasi. Kemudian dibuat relasi-relasi dengan atribut yang bukan key sehingga didapat informasi yang dapat diketahui hubungan relasi antar atribut.

Basis data biasa dikenal dengan database merupakan kumpulan informasi yang disimpan secara sistematis dalam perangkat komputer sehingga dapat dicari dan diperiksa melalui suatu program komputer saat informasi sedang dibutuhkan. Setelah diproses dengan memasukan data-data surat masuk dan keluar maka didapatkan hasil keluaran data informasi yang dibutuhkan. 


\section{Normalisasi studi kasus surat masuk dan keluar}

Tahap sebelum normalisasi bentuk form normal tahap satu, dimana atribut memiliki nilai tunggal pada satu baris (record), tiap file memiliki satu pengertian dan tidak ada set atribut ganda atau berulang. Berikut tabel sebelum normalisasi surat masuk ke SDN Genurit 2021. Disusun tahap sebelum normalisasi keluar masuk dengan nomor agenda 01, 02, 03, catatan tanggal masuk, nomor surat, tanggal surat diterima dan perihalnya. Catat juga ID pengirim, ditujukan kepada siapa, ID sifat surat, ID tata usaha dan catatan file bila diperlukan. Kemudian disusun daftar tabel normalisasi awal dan pada saat memasukan data surat masuk jika terdapat data yang sama tidak harus mengetik lagi. (Hasil analisis observasi pada 10 Februari 2021).

Pada tahap normalisasi awal surat keluar SDN Genurit disusun dan dicatat berdasarkan nomor agenda surat keluar, tangga lsurat, nomor surat, perihal, tujuan, ID sifat surat, ID tata usaha dan file catatan yang dibutuhkan. Kemudian dibuat tahap normalisasi lanjut untuk menyempurnakan data setiap entitas sehingga memiliki korelasi dengan entitas lainnya. Susunan didasarkan pada tahap normalisasi awal dengan penyusunan yang lebih lengkap dan data yang lebih akurat. Nomor agenda, tanggal diterima surat, nomor surat, perihal, ID pengirim, tujuan, ID sifat surat dan ID tata usaha dan file. Data surat masuk diatas sudah lebih baik penyusunan data dan akan disempurnakan lagi dalam tahap 2 normalisasi.

Selanjutnya dibuat normalisasi surat keluar agar sesuai dengan relasi antar atribut. Susunan disusun dari tahapan normalisasi awal dan disempurnakan dalam tahap normalisasi. Pada normalisasi surat masuk dan keluar ini, data sudah lebih lengkap dibandingkan dengan normalisasi awal, tetapi dengan adanya sebuah ID unik yang terdapat pada tabel akan membingungkan bagi pembaca atau orang yang tidak mengetahui maksud dari ID unik tersebut. Setelah dilakukan normalisasi tahap 2 didapatkan tabel surat masuk sebagaimana yang tercantum pada tabel di bawah ini:

Tabel 1. Surat Masuk

\begin{tabular}{|l|l|l|l|l|}
\hline $\begin{array}{l}\text { No_Agenda } \\
\text { SM }\end{array}$ & Tanggal_Diterima & Nomor_Surat & Tanggal_Surat & Perihal \\
\hline 01 & 04februari 2021 & 02/upt/ii/2021 & $\begin{array}{l}\text { 02februari } \\
2021\end{array}$ & $\begin{array}{l}\text { Pelaksanaan } \\
\text { oridifteri } \\
\text { Putaran kedua }\end{array}$ \\
\hline 02 & 09februari 2021 & 14/upt/ii/2021 & $\begin{array}{l}08 \text { februari } \\
2021\end{array}$ & $\begin{array}{l}\text { pembinaan } \\
\text { tempat } \\
\text { pengelolaan }\end{array}$ \\
\hline
\end{tabular}




\begin{tabular}{|l|l|l|l|l|} 
& & & & makanan \\
\hline 03 & 04April 2021 & $\begin{array}{l}\text { 33/Y- } \\
\text { HU/IV/2021 }\end{array}$ & 02April 2021 & Mohon ijin \\
\hline
\end{tabular}

\begin{tabular}{|l|l|l|l|l|}
\hline ID_pengirim & \multicolumn{1}{|c|}{ tujuan } & $\begin{array}{l}\text { ID_sifat_ } \\
\text { surat }\end{array}$ & ID_tata_usaha & File \\
\hline UPKEC & $\begin{array}{l}\text { Kepala } \\
\text { sekolah }\end{array}$ & SP & 1100561 & \\
\hline UPKEC & $\begin{array}{l}\text { Kepala } \\
\text { sekolah }\end{array}$ & SP & 1100561 & \\
\hline YHU & $\begin{array}{l}\text { Kepala } \\
\text { Sekolah }\end{array}$ & SB & 1100561 & \\
\hline
\end{tabular}

Susunan tabel surat keluar SDN Genurit 2021, dengan susunan nomor agenda, tanggal diterima, nomor surat, tanggal surat, perihal, ID pengirim, tujuan, ID sifat surat, ID tata usaha dan file catatan disusun sebagaimana yang tercantum pada tabel di bawah ini:

Tabel 2 Surat Keluar

\begin{tabular}{|l|l|l|l|l|}
\hline $\begin{array}{c}\text { No_Agenda } \\
\text { SK }\end{array}$ & Tanggal_Surat & Nomor_Surat & Perihal & Tujuan \\
\hline 01 & $\begin{array}{l}10 \text { Februari } \\
2020\end{array}$ & $\begin{array}{l}01 / \text { gnrt/ii/202 } \\
0\end{array}$ & Libursekolah & Seluruhsiswa/i \\
\hline 02 & $\begin{array}{l}25 \text { februari } \\
2020\end{array}$ & $\begin{array}{l}02 / \text { gnrt/ii/202 } \\
0\end{array}$ & LegalisirSK & BKD \\
\hline 03 & 01 Maret2020 & $\begin{array}{l}03 / \text { gnrt/iii/202 } \\
0\end{array}$ & LegalisirSK & BKD \\
\hline
\end{tabular}

\begin{tabular}{|l|l|l|}
\hline ID_sifat_surat & ID_tata_usaha & File \\
\hline SB & 1100561 & \\
\hline SP & 1100561 & \\
\hline SP & 1100561 & \\
\hline
\end{tabular}

Kemudian dibuat normalisasi tahap dua dengan membuat tabel surat-surat dan membuat HirearchyInput Process Output (HIPO) berupa urutan mulai dari awl proses sampai pada hasil output keluaran. Kamus data setiap entitas disusun agar memudahkan 
antar relasi yaitu kamus data surat masuk, kamus data surat keluar dan kamus data tata usaha, kamus data pengirim, serta kamus data sifat surat.

\section{Tahapan implementasi surat masuk dan keluar}

Pada tahap implementasi untuk memudahkan masuk (login) maka dibuat desain login masuk dengan email dan password. Kemudian setelah berhasil masuk ke dalam sistem maka akan tampil menu utama dalam pencarian surat masuk dan keluar (Hasil analisis sistem, Mona Setia Ningrum, 06 April 2021), sebagaimana ditampilkan dalam gambar di bawah ini:

Gambar 1. Implementasi Surat Masuk dan Keluar

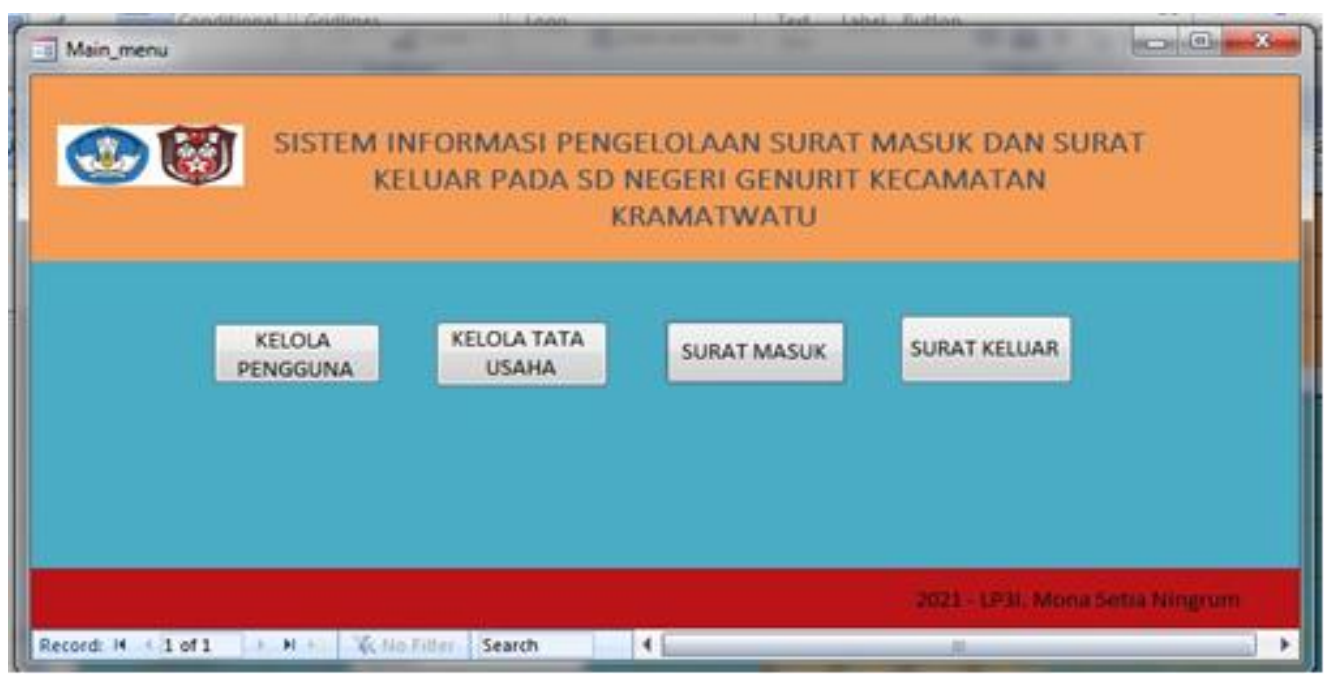

Pada input data yaitu pada surat masuk entry data dan surat dapat diinput oleh tata usaha sebagai operator entri data surat masuk dan keluar. Pada kelola tata usaha dicatat ID tata usaha dan nama tata usaha. Contoh entri data surat masuk sebagaimana yang ditampilkan pada gambar di bawah ini:

Gambar 2. Entri Data Surat Masuk

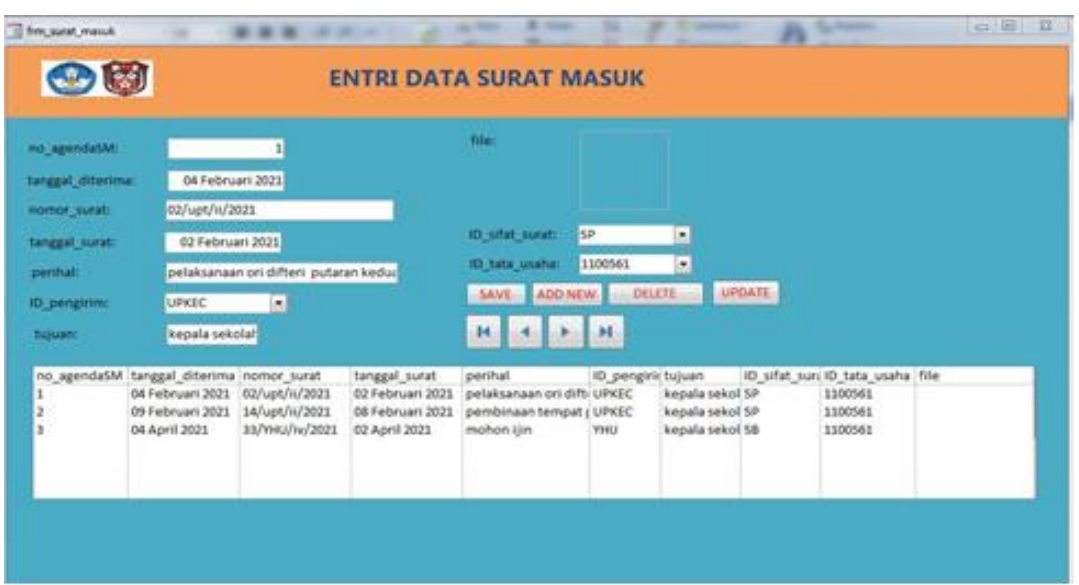


Selanjutnya dibuat laporan surat masuk pada sekolah dan kemudian dilaporkan untuk kepala sekolah. Dan juga laporan surat keluar dari kepala sekolah ke instansi lain. Surat keluar dari sekolah dapat ditampilkan dalam layar seperti yang ditampilkan dalam gambar di bawah ini:

Gambar 3. Laporan Surat Masuk

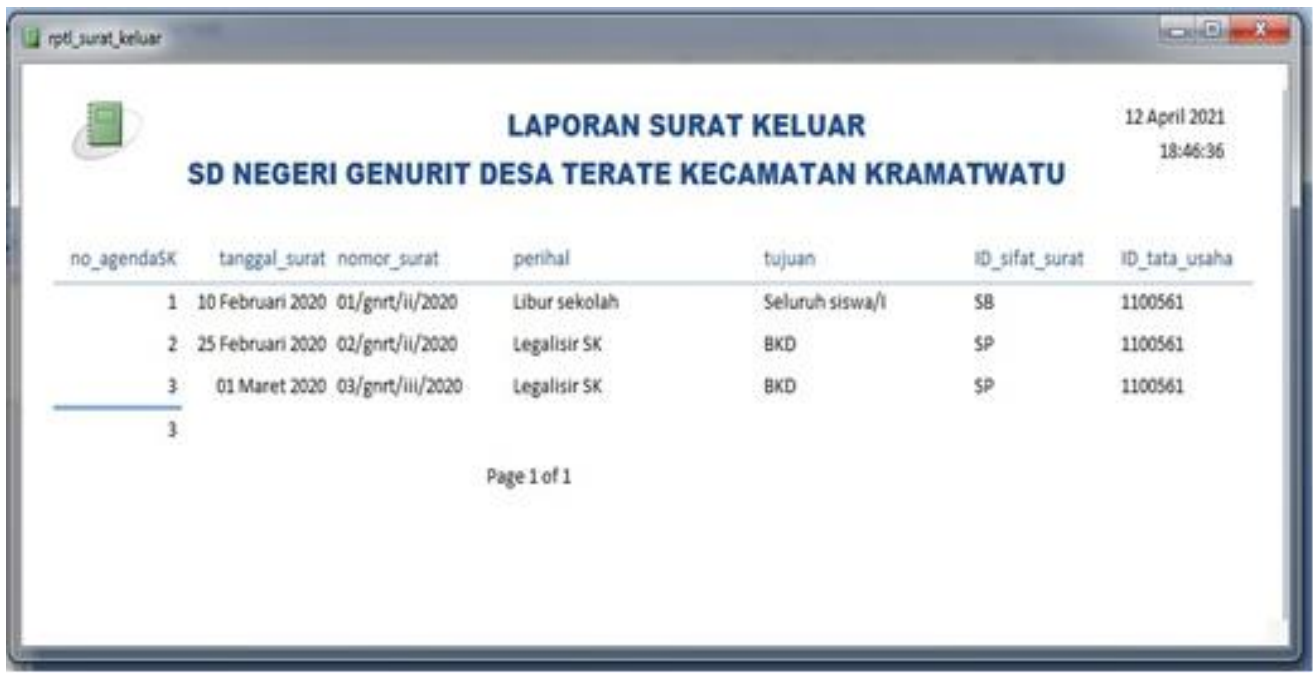

\section{KESIMPULAN}

Berdasarkan hasil penelitian mengenai sistem informasi pengelolaan surat masuk dan surat keluar pada SD Negeri Genurit maka dapat diambil kesimpulan sebagai berikut:

1. Proses pengelolaan surat masuk dan surat keluar pada SD Negeri Genurit saat ini cukup baik namun kurang efisien dikarenakan pencatatan surat masuk dan surat keluar masih secara manual dengan menggunakan buku besar.

2. Ditemukan beberapa hambatan yang dihadapi dalam pencatatan menggunakan buku besar yaitu dapat menimbulkan penumpukan dan pencatatan data, pencarian data kurang efisien karena membutuhkan waktu yang lama, kesulitan dalam pembuatan laporan. Penyimpanan pada buku bisa menimbulkan kerusakan pada buku catatan.

3. Sistem program informasi pengelolaan surat masuk dan surat keluar pada SD Negeri Genurit Banten mampu melakukan pencarian data secara cepat dan tepat, dan dapat melakukan penyimpanan data dalam jumlah banyak serta data yang tersimpan aman sehingga terhindar dari kerusakan.

\section{DAFTAR PUSTAKA}

Ansor, AS dan Muttahidah. (2016). Pengantar Manajemen, Manajemen Principle. Jogjakarta: Fajar Media Press. 
Asmani, JM. (t.t.). Manajemen Pengelolaan dan Kepemimpinan Pendidikan Profesional. Jogjakarta: Diva Pres.

Bogdan, RC and B Sari K. (2007). Qualitative Research for Education. Boston: Pearson Education.

Daft, RL. (2010). Era BaruManajemen New Era Management. Jakarta: Salemba Empat.

Dasril Aldo. (2021). PengantarTeknologiInformasi. Sumatra Barat: CV Insan Cendekia Mandiri.

Darmawan, Deni. (2012).Teknologi Informasi dan Komunikasi. Bandung: PT Remaja Rosdakarya.

Fathansyah. (2004). Buku Teks Komputer Basis Data. Informatika. Bandung.

Lestari, Ayu Dewi. (2014). Pengertian Surat Masuk dan Surat Keluar \& Pola Kegiatan Administrasi. https://www.google. com/amp/s/ayudewilestar101. wordpress.com /2014/05/08/pengertian-surat- masuk-dan-keluar-pola - kegiatanadministrasi/amp,[Diakses21 April2021]

Madcoms. (2016). Kupas Tuntas Microsoft Access 2016. Yogyakarta: Andi.

Mulyadi. (2016).Perancangan Sistem Informasi Akuntansi Penggajian Berbasis Komputer Pada PT Ladang Makmur. Politeknik Sriwijaya Palembang.

Mulyati dan Komariah. (2009). Manajemen Pendidikan. Bandung: AlfabetaTim dosen UPI Bandung.

Musdalifah. (2021). Implementasi sistem manajemen sekolah dalam pelayanan mendukung administrasi Manajemen Pendidkan Islam, S-1 Tarbiyah, http://repositori.uin-alauddin.ac.id/10087/1/SKRIPSI\%20IFA.pdf. Akses pada 09.06.2021.

Nuraida, Ida. (2013). Penanganan Surat Masuk dan Surat Keluar Di Subbagian Tata Usaha dan Arsip Bagian Umum Secretariat Daerah Kota Pariaman,2(1).

Prawiro M. (2021). Pengertian Surat Masuk dan Surat Keluar Fungsi Tujuan dan Jenisnya, Mei 2018.https://www.maxmanroe.comvid/surat/pengertian-surat-masukdan-surat-keluar.

Pujianto dan Rasidi. (2021). Pengembangan SIM Data Sekolah Di Kabupaten OKU, https://media.neliti.com/media/publications/171330-ID-pengembangan-sisteminformasi-manajmen-d.pdf.. Akses pada 09.06.2021.

Sarwandi. (2017). Jago Microsoft Access 2016. Jakarta: PT Elek Media Komputindo.

Siti Munasa Hidayat. (2018). Aplikasi Sistem Informasi Akuntansi Penjualan Tunai Gas $L P G$.

Sugiyono. (2012). Metode Penelitian Kuantitatif, Kualitatif, dan R\&D.Bandung: Alfabeta.

Suryanegara, Edi, dkk. (2021). Sistem Informasi Manajemen. Februari: Yayasan Kita Menulis.

Zainal A, Hasibuan. (2007). Metode Penelitian Pada Bidang Ilmu Komputer dan Teknologi Informasi. Fakultas Ilmu Komputer: Universitas Indonesia. 